\title{
Pemanfaatan System Informasi Mobile Bagi Kesehatan Ibu Hamil dan Anak
}

\author{
Rini Wahyuni Mohamad \\ Program Studi Magister Keperawatan Universitas Indonesia \\ Email: $\underline{\text { rinimohamad91@gmail.com }}$
}

\begin{abstract}
Abstrak
Kesehatan merupakan kebutuhan dasar bagi setiap orang dan sebagai faktor penentu keutamaan atau keunggulan dari sumber daya manusia. Namun demikian, kesehatan sering terlupakan karena berbagai macam faktor, dimana faktor yang paling sering adalah karena kesibukan individu itu sendiri. Selama ini para ibu untuk mendapatkan informasi tentang kehamilan dan anak berasal dari posyandu atau puskesmas serta dari bidan, perawat atau dokter di lingkungan sekitar mereka. Kekurangan dari fasilitas layanan kesehatan tersebut adalah waktu pelaksanaannya yang tidak bisa dilakukan setiap saat, serta kesibukan dan jarak yang cukup menyulitkan dalam mendapatkan informasi tersebut. Studi ini bertujuan untuk memberikan informasi mengenai alternative pemenuhan informasi bagi kesehatan ibu hamil dan anak dengan menggunakan system informasi mobile dalam bentuk aplikasi beserta panduannya pada Android. Metode yang digunakan dalam studi ini adalah Observasi dan literatur review. Adapun hasil dari studi ini adalah panduan sistem informasi mobile dalam bentuk aplikasi yang sangat bermanfaat bagi ibu hamil untuk mendapatkan informasi seputar kehamilan berdasarkan parameter-parameter yang dibutuhkan untuk setiap menu-nya. Kesimpulan pada penelitian ini adalah sistem informasi yang berbasis Android ini dibuat untuk membantu pemantauan kesehatan pada ibu hamil dan anak yang ada dalam kandungannya.
\end{abstract}

Kata Kunci: Sistem informasi mobile, Kesehatan, Kehamilan.

\begin{abstract}
Health is a basic need for everyone and as a determining factor for the priority or excellence of human resources. However, health is often forgotten due to various factors, where the most frequent factor is due to the individual's own busy life. So far, mothers to get information about pregnancy and children come from posyandu or puskesmas as well as from midwives, nurses or doctors in their neighborhood. The disadvantages of these health care facilities are that the implementation cannot be held at any time, as well as the busyness and distance makes it difficult to obtain this information. This study aims to provide information regarding the fulfillment of alternative information for the health of pregnant women and children by using a mobile information system in the form of an application and guide on Android. The method used in this study is observation and literature review. The result of this study is a mobile information system guide in the form of an application that is very useful for pregnant women to get information about pregnancy based on the parameters needed for each menu. The conclusion of this study is an Android-based information system designed to help improve the health of pregnant women and children in their womb.
\end{abstract}

Keywords: Mobile information system, Health, Pregnanc

\section{Pendahuluan}

Teknologi informatika khususnya

perkembangan komputer saat ini berperan

besar dalam memberikan bantuan kepada

manusia untuk mengatasi berbagai macam

persoalan baik dalam bidang industri, perdagangan, pendidikan, dan hampir seluruh bidang kehidupan manusia (Ratnasari et al., 2018). Komputer, handphone atau alat elektornik lainnya telah digunakan secara luas, terutama dalam bidang Kesehatan. Komputer / mesin saat ini yang dilengkapi dengan berbagai kemampuan mampu mengenali kondisi manusia, salah satunya terkait dengan kesehatan (Zulfadhilah, 2019). Sistem informasi kesehatan (SIK) adalah salah satu dari 6 building block atau merupakan komponen utama dalam suatu sistem Kesehatan (Setiyadi \& Hakam, 2015). 
Penerapan teknologi komputer dalam bidang kesehatan sampai pada saat ini sudah sangat banyak, contohnya tentang penggunaan Sistem Pakar Diagnosa Gangguan Kehamilan Dengan Metode Forward Chaining yang dilakukan oleh (Dwi Ratnasari \& Sutariyani, 2015).

Android termasuk dalam salah satu sistem operasi yang dipergunakan pada telepon celullar dan pada komputer tablet layar sentuh (touch screen) dengan berbasis Linux (Kasman, 2015). Basis sistem operasi android yaitu kernel linux yang merupakan open source sehingga sistem operasi android memungkinkan pengembang untuk selalu menciptakan aplikasi android sendiri yang bisa digunakan untuk macam-macam alat yang bergerak (mobile). Selain itu penggunaan teknologi dalam deteksi dini gangguna psikologis pada anak yang dilakukan oleh (Zulfadhilah, 2019) pada penelitiannya. kemudian penelitian yang dilakukan oleh (Krisnanik, 2017) tentang Perancangan

Model Basis Data Berbasis Pakar Gangguan Rahim Dan Kesehatan Janin serta penelitian yang dilakukan oleh (Mambang \& Byna, 2017) tentang Analisis Perbandingan Algoritma C.45, Random Forest Dengan Chaid Decision Tree Untuk Klasifikasi Tingkat Kecemasan Ibu Hamil. Keluhan yang dirasakan setiap Ibu yang satu dengan yang lainnya itu berbeda, begitu juga dengan keluhan pada masingmasing anak berbeda (Purwoastuti \& Walyani, 2014) sehingga diperlukan penyelesaian yang berbeda pada setiap keluhan yang dirasakan oleh ibu hamil dan anak, sehingga sangat diperlukan monitoring kesehatan ibu hamil dan anak lewat aplikasi dengan dilakukannya pengaturan terlebih dahulu agar aplikasi bisa dibangun sesuai dengan perancangan yang digambarkan. Monitoring merupakan tindakan untuk pengambilan keputusan terhadap ibu hamil dan anak untuk mengatasi kejadian sebelumnya pada pasien seperti pengamatan untuk perkembangan janin yang memudahkan untuk nemukan jika ada temuan perkembangan yang tidak normal (Tawakal, Imaduddin, \& Prasetyo, 2015), sehingga dapat diberikan penanganan sejak dini dan mengurangi gangguan maupun resiko bagi pasien seperti Ibu hamil. Jika ditemukan dalam perkembangan sudah terdapat gangguan gangguan maka setidaknya dapat mengurangi resiko (Pratiwi \& Restanty, 2018).

Berdasarkan hal tersebut membuktikan bahwa semakin bermanfaatnya kemajuan teknologi saat ini sehingga mampu membantu masyarakat. Pada penelitian ini akan dibahas tentang sebuah sistem informasi untuk ibu dan anak dengan menggunakan media smartphone 
Android, hal ini diharapkan dengan adanya android mobile ini bisa membantu para ibu dan anaknya untuk selalu mengetahui tentang hal-hal terkait tentang kesehatan pada ibu dan pada anak, agar selalu dalam keadaan sehat.

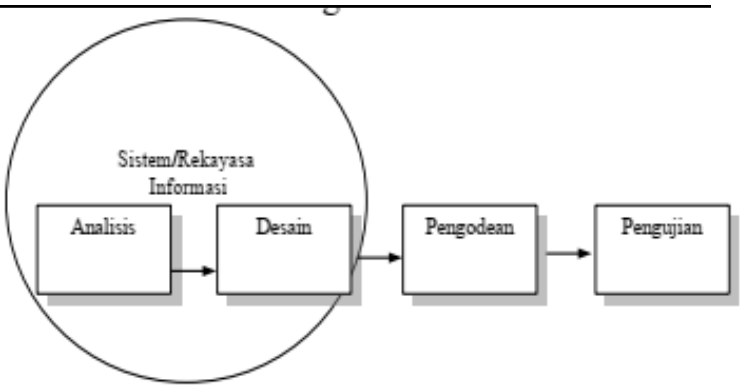

Gambar 1 Kerangka Penelitian

\section{Metode}

Proses penelitian ini dilaksanakan dengan melakukan observasi dan literature review dengan melibatkan mahasiswa jurusan kebidanan serta studi literatur untuk mengetahui apa saja yang diperlukan dalam sistem informasi yang dapat dibuat. Secara umum atau objek dari penulisan yakni: perawat dan bidan sebagai pengguna dalam rancangan aplikasi, rancangan meliputi registrasi, login, input biodata ibu hamil dan anak, dan pencatatan kesehatan ibu hamil (konseling) sehingga dapat memperlihatkan riwayat kesehatan ibu hamil sebagai bentuk monitoring. Pada pembuatan rancang bangun sistem informasi ini dilakukan dengan menggunakan SDLC (System Development Life-Cicle) yang termasuk dalam salah satu metode dalam pengembangan atau pembuatan sebuah aplikasi atau software. Metode ini juga menjadi kerangka penelitian seperti gambar dibawah:

1) Analisis: Pada tahapan ini analisis sudah masuk dalam pembuatan diagram aktifitas dan use case yang merupakan diagram dialog antar pengguna dengan sistem.

2) Design: Pada tahapan ini dilakukan pembuatan gambaran awal dari sistem, cara kerja sistem, dan antar muka sistem yang akan dibuat. Kegiatan yang dilakukan dalam perancangan meliputi perancangan database dan perancangan antarmuka.

3) Pengkodean: Pada tahapan ini sudah masuk pada implementasi pembuatan program sistem informasi yang dimaksud.

4) Pengujian: Tahapan ini dilakukan untuk mengetahui apakah prosedur yang digunakan dalam mengolah data menjadi informasi yang diharapkan atau tidak.

Dengan pengujian tersebut pengguna dalam hal ini ibu dapat memberika pendapatnya mengenai sistem android mobile ini. 
Pada penelitian yang telah dilakukan didapatkan hasil berupa sebuah sistem informasi tentang ibu hamil dan anak yang disajikan dalam bentuk mobile, sehingga bisa digunakan pada smartphone android. Aplikasi ini merupakan aplikasi mobile berbasis android yang berguna untuk mendapatkan informasi-informasi bagi ibu hamil dan anak berdasarkan parameter-parameter yang dibutuhkan untuk setiap menunya. Fitur utama sistem ini adalah informasi tentang keadaan ibu hamil dan anak/janin. Penggunaan fitur tersebut mengharuskan memasukkan tanggal terakhir haid, berat badan ibu hamil, dan tinggi ibu hamil. Dari inputan tersebut akan diketahui berat badan ideal ibu hamil, perkiraan tanggal kelahiran, dan umur janin. Setelah diketahui umur janin, pengguna dapat melihat informasi mengenai perkembangan janin dengan usia janin yang telah diketahui tadi. Berdasarkan umur janin tadi, aplikasi juga akan memberikan informasi senam bagi ibu hamil sesuai dengan umur dari janin yang dikandung ibu. Semua data-data informasi tadi direkap kedalam database tiap minggunya untuk mengetahui perkembangan kesehatan ibu hamil berdasar berat badan ideal ibu hamil tersebut. diberi informasi mengenai kebutuhan gizi ibu mingguan berdasarkan perkembangan ibu hamil. Pada aplikasi ini juga terdapat beberapa fitur tambahan guna membantu ibu hamil dan anak dalam mendapatkan informasi kesehatan mereka. Adapun fiturfitur tambahan tersebut adalah untuk mengetahui subur wanita, penanganan keluhankehamilan, pencatat waktu kontraksi pada ibu hamil, penentu kesehatan anak, menghitung kebutuhan air harian, panduan merawat payudara bagi ibu hamil dan menyusui, serta penentuan lokasi rumah sakit bersalin terdekat. Pada gambar di bawah ini merupakan antarmuka sistem atau aplikasi yang telah dibuat oleh penulis Halaman splash screen merupakan halaman pembuka atau yang pertama kali muncul ketika program dijalankan, dan halaman ini dapat tertutup secara otomatis yang kemudian bisa langsung mengarah ke halaman menu utama.

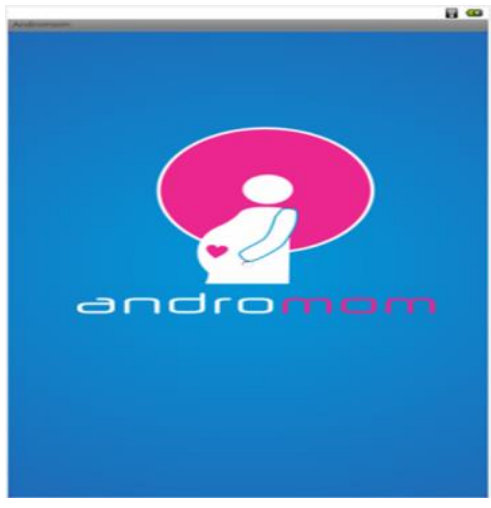

Gambar 2. Form Loading 


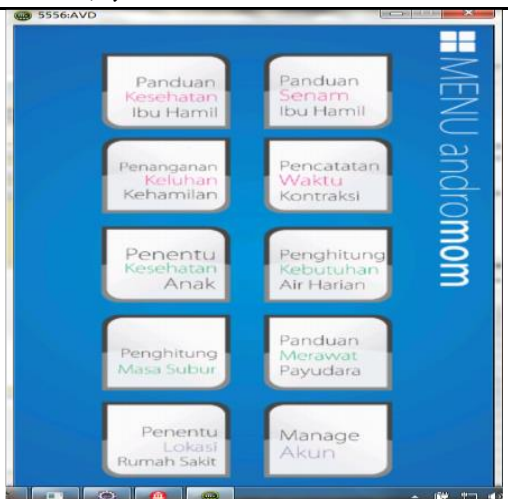

Gambar 3. Form Utama.

Pada gambar di atas merupakan beberapa form antar muka pada aplikasi yang dibuat oleh peneliti. Halaman menu utama adalah halaman yang muncul setelah halaman splash screen. Halaman ini berisi fitur-fitur dari aplikasi panduan untuk ibu hamil dan anak berbasis android mobile.

\section{Pembahasan}

Sistem informasi pemantauan dan evaluasi pelayanan kesehatan dasar pada Ibu dan Anak berbasis android mobile dirangkai dengan fitur berupa fungsi-fungsi yang sesuai dengan kebutuhan ibu dan anak. Sistem android mobile dibuat untuk membantu koordinator Kesehatan Ibu dan Anak (KIA). Pada masa ini membangun dan mengembangkan perangkat lunak diperlukan perancangan spesifikasi perangkat lunak yang tepat agar perangkat lunak yang akan dikembangkan memiliki deskripsi fungsi yang sesuai dengan yang dibutuhkan pada masing-masing pengguna (Pratama, Sulistiowati, \& Maulana, 2016). Android mobile membantu untuk membangun sistem sehingga sistem yang telah dibuat dapat dianalisis agar dapat mengetahui keefektifannya seperti perancangan aplikasi yang dapat digunakan pada android mengenai kesehatan ibu dan anak. Pada aplikasi ini terdapat beberapa fitur yang sangat diperlukan oleh ibu dan anak.

Dari fitur-fitur tersebut ibu dan anak bisa mendapatkan informasi penting tentang hal-hal yang berhubungan dengan kesehatan ibu dan anak. Informasi tentang kesehatan ibu dan anak, kemudian informasi perkembangan janin dan lainnya. Aplikasi ini juga memberikan informasi tentang senam hamil yang merupakan olahraga yang sangat baik dan bisa membantu ibu hamil tetap bugar, hal ini juga disampaikan oleh (Pujiastuti, 2014) tentang pentingnya senam pada ibu hamil. Selain itu (Pujiastuti, 2014) menyebutkan bahwa perlunya informasi tentang kehamilan pada wanita yang hamil anak pertama, karena diketahui oleh para wanita yang sedang hamil anak pertama banyak hal yang belum pernah dirasakan sebelumnya. Pengetahuan terkait kehamilan sangat diperlukan oleh wanita yang hamil baru pertama kali hamil, seperti mengalami fase pembukaan 1 sampai 10 . Berdasarkan dari penelitian yang dilakukan oleh (Elliana \& Kurniawati, 2015) menyebutkan bahwa dengan adanya 
penggunaan teknologi android mobile

seluler sebagai strategi promosi Kesehatan diharapkan mampu memfasilitasi informasi lebih lengkap dan akurat, menjangkau individu sehat tetapi tidak teratur datang ke pelayanan kesehatan. Berdasarkan hal tersebut maka aplikasi/system android mobile yang telah dibuat ini bisa menjadi media promosi kesehatan khususnya pada ibu dan anak.

Berdasarkan panduan kesehatan bagi ibu dan anak berbasis android mobile dapat direkomendasikan penggunaan tersebut dalam pelayanan bidang pediatric, bidang maternitas, baik kedokteran, perawatan maupun ahli gizi di Indonesia. Kemudahan dan akurasi yang telah dibuktikan serta tuntutan dan perkembangan teknologi informasi pada pengguna pelayanan Kesehatan khususnya bidang keperawatan, hal ini sangat memungkinkan untuk diterapkan di Indonesia. Dengan pencatatan otomatis ini akan memperingan kerja perawat di Indonesia, mengingat beban kerja perawat masih menjadi keluhan utama rata-rata pelayanan keperawatan di Indonesia.

\section{Simpulan}

Perkembangan IT saat ini dalam pendidikan keperawatan meningkatkan inovasi dalam metode pembelajaran dan memperluas area penelitian. Pemanfaatan
IT yang ikut serta membantu sebagai media pembelajaran harus disesuaikan dengan kurikulum pendidikan dalam hal ini adalah pendidikan keperawatan. Untuk pemenuhan sistem informasi kesehatan ibu hamil dan anak yang lebih cepat saat ini telah banyak terdapat aplikasi-aplikasi berjenis mobile yang mampu memenuhi kebutuhan informasi kesehatan ibu hamil dan anak.

\section{Daftar Pustaka}

Dwi Ratnasari, D., \& Sutariyani. (2015). Sistem Pakar Diagnosa Gangguan Kehamilan Dengan Metode Forward Chaining. Jurnal ilmiah go infotech, 21(2), 25-31.

Elliana, D., \& Kurniawati, T. (2015). Perbedaan Pengetahuan Dan Persepsi Ibu Hamil Terhadap Penerapan Model Sms Gateway. Jurnal Kesehatan Masyarakat, 10(2), 203. https://doi.org/10.15294/kemas.v10i 2.3382

Firmansyah, Y., \& Udi, U. (2017). Penerapan Metode SDLC Waterfall Dalam Pembuatan Sistem Informasi Akademik Berbasis Web Studi Kasus Pondok Pesantren Al-Habib Sholeh Kabupaten Kubu Raya, Kalimantan Barat. Jurnal Teknologi Dan Manajemen Informatika, 4(1). https://doi.org/10.26905/jtmi.v4i1.1 605

Hendrata, T. W., Arifin, A., \& Hikmah, N. F. (2016). Sistem Monitoring Elektrokardiografi Berbasis Aplikasi Android. JURNAL TEKNIK ITS, 99-105. 
Kasman, A. D. (2015). Trik Kolaborasi Android dengan PHP dan MySQL. Yogyakarta: Lokomedia

Krisnanik, E. (2017). Perancangan Model Basis Data Berbasis Pakar Gangguan Rahim Dan Kesehatan Janin. Seminar Nasional Teknologi Informasi Dan Multimedia 2017.

Mambang, \& Byna, A. (2017). Analisis Perbandingan Algoritma C.45, Random Forest Dengan Chaid Decision Tree Untuk Klasifikasi Tingkat Kecemasan Ibu Hamil. Semnasteknomedia Online, 5(1), 103-108

Nuryasin. (2016). “Aplikasi Sistem Informasi Pendaftaran Wisuda Berbasis Online Studi Kasus FST UIN Syarif Hidayatullah Jakarta". Jurnal Ilmiah ISSN: 1979-0767.

Pratama, A., Sulistiowati, \& Maulana, Y. M. (2016). Rancang Bangun Sistem Informasi Pemantauan Dan Evaluasi Pelayanan Kesehatan Dasar Pada Ibu Berdasarkan SPM. Jurnal Sistem informasi dan Komputer Akuntansi (JSIKA), 1-10.

Pratiwi, I. G., \& Restanty, D. A. (2018). Penerapan Aplikasi Berbasis Android "Status Gizi Balita Terhadap Pengetahuan Ibu Dalam Pemantauan Status Gizi Anak Usia 12-24 Bulan". JKAKJ, 8-14.

Pujiastuti, A. (2014). Konsep Kehamilan Sehat: Upaya Mencetak Generasi Cerdas. Artikel Kesehatan
Nasional, 1-9. http://eprints.uad.ac.id/8172/1/kons ep

Ratnasari, D., Qur'ani, D. B., \& Apriani, A.(2018). Sistem Informasi Pencarian Tempat Kos Berbasis Android. Jurnal INFORM, 3(1), 32-45.

https://doi.org/10.25139/ojsinf.v3i1 .657

Rusdiana, L., Sediyono, E., \& Surarso, B. (2015). Studi Implementasi Adaptive Neuro Fuzzy Inference System Untuk Menentukan Normalitas Kehamilan. Jurnal Sistem Informasi Bisnis (JSINBIS), 98-108.

Setiyadi, N. A., \& Hakam, F. (2015). Analisis Pelaksanaan Sistem Informasi Kesehatan di Klinik Muhammadiyah Medical Center (MMC) Universitas Muhammadiyah Surakarta. Jurnal IKESMA, 11(Mmc), 15-24.

Tawakal, H. A., Imaduddin, Z., \& Prasetyo, I. (2015). Sistem Informasi dan Monitoring Perkembangan Janin Berbasis Android. Jurnal Teknologi Terpadu, 31-37.

Zulfadhilah, M. (2019). Sistem Pakar Untuk Diagnosa Gangguan Psikologis Anak Dengan Algoritma Breadth First Search (BFS). JITEKH, 7(1), 15-2 